\title{
POLÍTICAS PÚBLICAS NO BRASIL E O LUGAR DO SUJEITO: LEI, JUSTIÇA E REPRESENTAÇÕES SOCIAIS NO ACESSO À EDUCAÇÃO SUPERIOR BRASILEIRA E NAS ESTRATÉGIAS EFETIVAS DE PERMANÊNCIA
}

\author{
Débora de Abreu Moreira dos Santos Martins** \\ Maria Carolina Carvalho Motta***
}

\section{RESUMO}

O presente artigo discute se há consonância das ações afirmativas, ou discriminações positivas, com o princípio constitucional da igualdade. Para tanto, pontua-se os principais momentos históricos relacionados com a educação, bem como algumas estruturas legais construídas ao longo do tempo e as disparidades no acesso à educação superior. Conceitua-se o princípio da igualdade para levantar a questão da aplicação efetiva do referido princípio no plano material. Por fim trata dos requisitos para a concessão de ações afirmativas para a mudança do status quo na educação superior no Brasil. Utilizou-se de pesquisa bibliográfica e documental na doutrina e nas jurisprudências brasileiras.

PALAVRAS-CHAVE: Ações afirmativas; Igualdade.; Educação Superior; Política pública.

\begin{abstract}
PUBLIC POLICIES IN BRAZIL AND THE PLACE OF CITIZEN: LAW, JUSTICE AND SOCIAL REPRESENTATIONS IN ACCESS TO BRAZILIAN HIGHER EDUCATION AND IN EFFECTIVE STRATEGIES OF PERMANENCE
\end{abstract}

\begin{abstract}
This paper discusses whether there is consonance of affirmative actions, or positive discriminations, with the constitutional principle of equality. This way, the main historical moments related to education as well as some legal structures built up over time and disparities in access to higher education. The principle of equality is conceptualized for the question of the effective application of this principle on the material plane. Subsequently, it presents the requirements for granting affirmative actions for the change in the status quo of higher education in Brazil. Bibliographical and documentary research was used, they have come from Brazilian doctrine and jurisprudence.
\end{abstract}

KEY- WORDS: Affirmative actions. Equality. College education. Public policy.

\footnotetext{
* Mestre em Direito pela Universidade Católica de Brasília (2011). Professora universitária da UniAnhanguera e PUC-GO. (martins184@gmail.com)

** Doutora em Ciências sociais - Estudos Comparados sobre as Américas pela UnB (2017). Professora efetiva da carreira do magistério superior do Curso de Direito na Universidade Federal de Goiás (UFG) Regional Goiás, área de concentração: Direito Administrativo, Financeiro e Tributário, em regime de Dedicação Exclusiva. (professora_mcarolina@ hotmail.com)

Rev. de Direito Sociais e Políticas Públicas | e-ISSN: 2525-9881 | Goiânia| v. 5 | n. 1 | p. 22-43| Jan/Jun. 2019 


\section{Introdução}

No Brasil, como no mundo, nas últimas décadas, se tornou constante a elaboração de políticas públicas que envolvem leis para a promoção da justiça e da igualdade. Contudo, vários autores apontam que no caso das leis brasileiras existe uma verticalização, ou seja, obediência à hierarquia da Constituição Federal, o que acaba trazendo um hiato entre a lei e sua aplicação. Isto é, para a execução das leis necessário se faz a ocorrência de políticas públicas no sentido da Constituição Federal. É neste sentido que o artigo apresenta tal discussão como objetivo, discutindo a relação entre leis, políticas públicas e justiça social (combate à desigualdade) e a invisibilidade social dos sujeitos que deveriam ser atendidos pelas políticas, com o apoio da Teoria das Representações Sociais. Os argumentos apresentados têm como foco as contradições encontradas, e no caso das políticas públicas, sua inadequação relativa a lei e seu "descaso" com a efetividade no combate à desigualdade social. O trabalho visa discutir a ineficácia jurídica, convalidada no sentido da promoção da justiça e da igualdade, não só pelo fato de serem verticalizadas, mas pelo modo como elas concebem os seus sujeitos.

O presente artigo vislumbra a relação entre estudos jurídicos brasileiros, tanto na vertente dos autores neoliberais, quanto daqueles fundados nas teorias socialdemocratas e tidos como socialistas como forma de melhor entender a situação desigual e conflitante no Brasil do século XXI e as desigualdades na vertente do estudo superior, especificando a política de cotas sociais existentes na tentativa de sanar tais questões. Tal política, compõe o rol das políticas afirmativas, presentes nos estudos da Ciência Política e da Ciência da Administração Pública, a priori das ações advindas do Poder Público, cujo o estudo, atualmente, ainda segue correlacionado a Ciência do Direito, especialmente no ramo do Direito Público Constitucional envolto pelos valores e pela dinâmica constante da política como instrumento, interdisciplinar, possibilitando aos pesquisadores voltar "os olhos" às demandas sociais, no sentido de realizar algum

Rev. de Direito Sociais e Políticas Públicas | e-ISSN: 2525-9881 | Goiânia | v. 5 | n. 1 | p. 22-43| Jan/Jun. 2019 
objetivo de ordem pública (Bucci, 2006), com o foco na ciência política ou na sociologia e nos estudos das condições de funcionamento do Estado liberal judicial.

Isso explica a tarefa constitucional na pesquisa sobre políticas públicas, com suportes advindos do texto constitucional: leis infraconstitucionais, assim como normas infralegais: instrumentos jurídicos de outra natureza, como contratos de concessão de serviço público, condicionando o artigo a promover a ilustração, em prol da defesa de seus argumentos, no recorte da política pública brasileira de acesso à educação superior e a discriminação positiva. $\mathrm{O}$ contexto é o das representações sociais promovidas pelo público-alvo, retratado pelo referido sistema de política pública, os cotistas e no porquê do conflito social, relativo ao público-alvo, salientando as contradições entre o que está disposta na Constituição Federal de 1988, no princípio da igualdade, previsto no caput do artigo $5^{\circ}$, importante para a construção da sociedade, e na aplicação das cotas para o acesso ao ensino superior, positivadas na Lei n. 12.711/12, bem como nas estratégias efetivas de permanência, Lei 12990/2014, ambas provindas do Estatuto da Igualdade Racial (Lei12.288/10). O elo entre tais medidas e o referido princípio não constitui uma unanimidade e está longe de ser tida como completa, vez que necessita seguir alguns parâmetros para ser juridicamente aceitável e compatível.

A análise do artigo demonstra a construção histórica da educação superior brasileira, relacionando o surgimento das disparidades entre os cidadãos e as principais estruturas normativas condizentes ao tema. E ainda, correlacionando-o com o estudo das discriminações positivas relativas ao princípio constitucional da igualdade no acesso ao ensino superior e o princípio da dignidade da pessoa humana, cominando, desse modo, para uma compreensão mais aprofundada sobre as discriminações positivas e, em especial, a discriminação referente às normas de Cotas.

\section{Políticas Públicas e o Acesso ao Ensino Superior no Brasil}

Os direitos sociais ganham a partir do século XX uma visão estruturada nos direitos fundamentais pois, com a sua concretização surge no Estado Liberal uma inovação no paradigma jurídico, modificando a postura abstencionista do Estado para o

Rev. de Direito Sociais e Políticas Públicas | e-ISSN: 2525-9881 | Goiânia | v. 5 | n. 1 | p. 22-43| Jan/Jun. 2019 
enfoque prestacional, próprio das obrigações de fazer oriundas dos direitos sociais. Segundo Bucci (2006), a necessidade de identificar e compreender as políticas públicas como categoria jurídico surge à medida que se buscam maneiras de concretização dos direitos humanos, em particular os direitos sociais, direitos-meios, ou seja, cuja a principal finalidade é assegurar que toda pessoa tenha condições de usufruir os direitos individuais. São exemplos: a Constituição Mexicana de 1917; a Constituição de Weimar de 1919 e a Constituição brasileira de 1934.

De acordo com Alves (1997), citando o Pacto Internacional sobre Direitos Econômicos, Sociais e Culturais, de 1966, artigo 2: "cada Estado-parte do presente Pacto, compromete-se a adotar medidas, tanto por esforço próprio como pela assistência e cooperação internacionais, principalmente nos planos econômico e técnico, até o máximo de seus recursos disponíveis".

Contudo, ainda segundo Alves (1997), os Estados, como o Brasil, que demoraram a criar condições de organização e funcionamento do Estado Liberal, no quesito liberdades e cidadania, identificam-se com a árdua tarefa constitucional de democratização mais onerosa, do que os Estados, como a Alemanha, pós nazismo, na sua Constituição de 1949, em que as tarefas básicas da civilização foram cumpridas desde esta data. Tal Constituição, serviu de modelo para a Constituição Brasileira de 1988, passando pela interferência da Constituição Portuguesa de 1976, na estruturação dos Direitos Fundamentais.

Para Hesse (1996) os direitos fundamentais evoluem no sentido de garantir a liberdade em relação as ameaças perpetradas, não mais pelo Estado, mais pelos poderes não estatais (forças econômicas e políticas exteriores ao Estado), existindo, neste sentido uma deficiência inerente aos direitos sociais no que concerne ao seu estatuto constitucional, na proporção em que tais direitos não agregam direitos subjetivos e que cujo descumprimento gera ações, frente ao Estado, dependente das tarefas legislativas deste. No Brasil, o desafio da democratização é inseparável da resolução das situações de desigualdades em relação às oportunidades sociais, na busca do controle da situação de subumanidade, identificando que tarefas sociais ainda estão por ser feitas.

Rev. de Direito Sociais e Políticas Públicas | e-ISSN: 2525-9881 | Goiânia| v. 5 | n. 1 | p. 22-43| Jan/Jun. 2019 
As políticas públicas pouco têm sido estudadas do ponto de vista que interessa a sociedade atual, ou seja, examiná-las sob o prisma sócio-jurídico atual, não é algo praticado, pois elas têm sido investigadas sob a ótica da ciência política, da sociologia, da economia política, da ciência da administração e, mesmo, da filosofia moral (GARCIA, 2009).

Necessário é conceituar o Estado Social, como campo de resposta aos problemas sociais. O Estado Social de hoje, em muitos países organizados por uma constituição democrática, é um elemento da realidade constitucional ao erigir como desafio a adaptação e resposta, sobretudo em relação a pobreza(s), quando as situações de sua imagem, da sua emergência e desenvolvimento se alteraram. Assim, “o Estado Social é produto da modernidade e, como tal, confronta-se com os desafios da pósmodernidade" (LOUREIRO, 2010, p. 115) e reergueu-se ao dar lugar ao Estado pósSocial que, por sua vez, caminha já para o Estado neossocial (ou Estado pós-póssocial), com uma relevante responsabilidade de garantia.

A reinterpretação dos direitos sociais e do princípio da socialidade à luz das ideias de cidadania e de responsabilidade não quer (nem pode), colocar em causa o Estado Social, até porque os problemas que lhe são normalmente imputados e que fundamentariam sua reforma, não se tratam de problemas do Estado Social em si, mas, em especial, do uso abusivo que lhe é conferido (MOREIRA, 2007). Em função do que se afirmou, não se pode ignorar a necessidade de modificar, aperfeiçoar o Estado Social com o intuito de erigir de forma sustentada o Estado neossocial (LOUREIRO, 2010).

O Estado de Bem-Estar reconstruído, deve, despedir-se dos aspectos burocráticos que lhe tolhem a eficácia e a adaptar-se às novas circunstâncias (Sampaio, 2014), caracterizando-se pela consolidação da compreensão da dignidade da pessoa humana, pelo aprofundamento da justiça distributiva e pela promoção entre a igualdade de todos os membros da comunidade. E, nesse pressuposto, ficam os poderes públicos obrigados a intervir para que a igualdade jurídico-política, a qual assegura o Estado Social (de Direito) a atribuição de conformação da ordem social com o intuito de alcançar a justiça social e a garantia das condições materiais do cidadão. De forma que pode-se afirmar, que os objetivos mais importantes do Estado Social passam a almejar:

Rev. de Direito Sociais e Políticas Públicas | e-ISSN: 2525-9881 | Goiânia | v. 5 | n. 1 | p. 22-43| Jan/Jun. 2019 
a segurança econômica e social; a redução das diversas desigualdades e a redução da pobreza (ZAMORA, 2007).

Com base nos pressupostos do Banco Mundial (BM), a educação é "a pedra fundamental para o desenvolvimento humano e redução da pobreza", e da Unesco (2005) “(...) um meio para desenvolver o capital humano, para melhorar o desempenho econômico e as capacidades e as escolhas individuais, a fim de desfrutar das liberdades de cidadania" (s/p). Partindo desta expectativa Minto (2001), apresenta que os princípios da economia da educação, formulada por Theodore W. Schultz, quando transladada para a educação, subsidiou uma concepção tecnicista do ensino e da organização da escola, que assume a concepção de que educar é pressuposto do desenvolvimento econômico do indivíduo, pois o ser humano e seu aprendizado, com base no capital, são estruturados por sua "função de engrenagens do sistema econômico" (MINTO, 2001).

É desta interseção do Estado de Bem Estar, fundado em princípios de solidariedade e com metas a diminuir as desigualdades, com a pretensão capitalista, neoliberal, de fazer do indivíduo uma peça do jogo econômico, que a educação superior no Brasil foi pensada e estruturada. O acesso às vagas nas instituições de ensino superior, no entanto, não conseguiu atingir o objetivo dos direitos sociais, qual seja, a disponibilidade em um contexto de igualdade de oportunidades. Muito embora o ensino superior no Brasil esteja aberto ao capital privado, são as universidades públicas os centros de excelência do país em matéria de ensino, pesquisa e extensão, pilares constitucionais deste campo. De forma que institucionalizado ficou o acesso às vagas gratuitas através de provas de conhecimento adquiridas na educação básica. $O$ denominado "vestibular", como requisito de acesso às universidades públicas perpetuou práticas meritocráticas para o ingresso na educação superior.

Essa igualdade de mérito, no entanto, ao invés de satisfazer práticas de exclusão tem o efeito perverso de distorção social e discriminatório. Isto porque o prêmio pelo mérito, puro e simples, tem como resultado uma concorrência desigual que coloca lado a lado indivíduos com construções sociais diferentes, exacerbando a competitividade entre aqueles que entregam o conhecimento exigido e os que foram

Rev. de Direito Sociais e Políticas Públicas | e-ISSN: 2525-9881 | Goiânia | v. 5 | n. 1 | p. 22-43| Jan/Jun. 2019 
socialmente excluídos dele. Há, portanto, uma distância entre o capital sociocultural dos concorrentes sem que haja por parte do Estado a preocupação em diminuí-la. Daí a razão pela qual o debate avança para a necessidade de políticas públicas a fím de desarticular e desconstruir esta lógica de exclusão. (SILVA, 2017)

\section{Políticas de "Cotas" no Ensino Superior no Brasil e nas estratégias efetivas de permanência: uma ilustração da discussão necessária}

As políticas públicas possuem a função própria que os direitos sociais assumem ao ser possível resumir a sua caracterização em quatro aspectos: $\left(1^{\circ}\right)$ a sua orientação em função do princípio da igualdade material; $\left(2^{\circ}\right)$ o seu vínculo com a satisfação de necessidades individuais; $\left(3^{\circ}\right)$ a intensificação do elemento público que atribui ao Estado a responsabilidade em matéria social; e $\left(4^{\circ}\right)$ a sua virtualidade como elementos que operam diante dos mecanismos do mercado (SAMPAIO, 2014).

O Brasil iniciou suas políticas públicas no quesito criação de universidades de forma tardia. Países da América Latina como o Peru e o México despontaram na criação de universidades; a Universidade de San Marcos, no Peru, existe desde 1551 e consta na lista das universidades mais antigas do mundo. Sob as ordens da Espanha, esses países não foram reprendidos pela criação de cursos superiores, de forma contrária, o Brasil, colônia de Portugal, foi desencorajado a criar cursos a nível superior, incentivando que os jovens das elites brasileiras fossem estudar em Coimbra. Tal situação foi alterada, quando a família real portuguesa veio para o Brasil, no século XIX, elevando o status do Brasil de mera colônia extrativista para sede das decisões do reino, com a valorização do fluxo comercial com os países aliados, tal como a Inglaterra, diante da abertura dos portos, assim como, com o investimento em bens industrializáveis e o favorecimento da estruturação de uma sociedade cultural. Criação de bibliotecas, teatros e academias científicas deram para o Brasil, principalmente no Rio de Janeiro, uma realidade sociocultural mais próxima da Europa (FAUSTO, 2003).

A Coroa precisou criar a administração interna e a necessidade de médicos, engenheiros e advogados se tornou preemente. Na verdade, esse modelo de política

Rev. de Direito Sociais e Políticas Públicas | e-ISSN: 2525-9881 | Goiânia | v. 5 | n. 1 | p. 22-43| Jan/Jun. 2019 
pública educacional estava distante de construir uma educação com liberdade, pois advinham dos ideais de controle da corte, favorecendo uma pequena classe elitizada (CUNHA, 2015). Entre as primeiras instituições de ensino superior do Brasil destaca-se a Escola de Cirurgia e Anatomia na Bahia fundada em 1808, hoje Faculdade de Medicina da Bahia (FMB), a Escola de Anatomia, Medicina e Cirurgia no Rio de Janeiro também em 1808, hoje Faculdade de Medicina da Universidade Federal do Rio de Janeiro (UFRJ), e, em 1827 a Faculdade de Direito de São Paulo, (atual Universidade de São Paulo (USP)). Com a Independência do Brasil em 1822, surgem políticas expansionistas com incentivos à educação superior, mas ainda precárias. Pontes, estradas, fábricas e serviços públicos básicos eram deficitários. Daí a necessidade de políticas públicas educacionais. Nesta esteira, criou-se os cursos de forma mais acelerada nesse período, porém ainda restritas às classes mais abastardas da sociedade, profissões liberais ou militares (Cunha, 2015). As classes menos favorecidas economicamente possuíam, em regra, uma mão de obra menos qualificada e mais direcionada para a formação técnica ou religiosa, salientando que no período em que vigorou a escravidão, os negros não eram considerados "pessoas" pelas leis brasileira, estavam, assim, em situação de paridade com “coisas”, Fausto (2003). A passagem para a categoria de "pessoas" pode ter se dado em 1888, com a conhecida "Lei Áurea", mas a inclusão de direitos perpassa por uma luta histórica contra práticas de discriminação, exclusão, preconceitos e racismo.

É, no entanto, com o advento do século XX e a Constituição Federal de 1988 no país, que a igualdade na modalidade material e formal passa a ser ponderada com equidade. Segundo John Rawls (2011), igualdade é um dos valores fundamentais na convivência política, atrelado a liberdade como valor supremo da vida humana. A Constituição Federal de 1988 traz em seu bojo os dois conceitos, contudo a realidade ainda está distante do contexto apregoado por Rawls (2011) na sua teoria da justiça como equidade (fairness). Pelo exposto, entende-se que o verticalismo político brasileiro contido nas formas principiológicas da Constituição atual, estão condizentes com a teoria de Rawls, mas a materialização desta verticalidade não está apresentada nas políticas praticadas, pois não se visualiza uma sociedade brasileira "bem-ordenada".

Rev. de Direito Sociais e Políticas Públicas | e-ISSN: 2525-9881 | Goiânia | v. 5 | n. 1 | p. 22-43| Jan/Jun. 2019 
Segundo Rawls (2011) esta sociedade "se configura como um sistema equitativo de cooperação entre cidadãos razoáveis e racionais".

Ressaltando que neste contexto, da justiça com Equidade (fairness) de John Rawls, a Constituição Federal apresenta dispositivos sobre as ações afirmativas, no quesito de promoção de políticas públicas ou privadas que possuem o objetivo de neutralizar os efeitos da discriminação de raça, gênero, idade, nacionalidade, aspectos físicos (GOMES, 2003). Segundo Gomes (2003), esta situação se torna viável quando o Estado investe em recursos (dinheiro e tempo) para evitar que pessoas sofram essa diferenciação, com base em seu gênero ou grupo étnico (CROSBY, IYER, \& SINCHAROEN, 2006). Visto que, a ação afirmativa objetiva possibilitar oportunidades iguais de modo proativo. A prática mais conhecida de ação afirmativa é o sistema de cotas, que consiste em "estabelecer um determinado número ou percentual a ser ocupado em área específica por grupo(s) definido(s), o que pode ocorrer de maneira proporcional ou não, e de forma mais ou menos flexível” (MOEHLECKE, 2002, p. 199).

A desigualdade do acesso ao ensino superior no Brasil pode ser observada ainda hoje nos números atuais: Pesquisa Nacional por Amostra de Domicílios (PNAD), realizados pelo IBGE que apontam que a informalidade no mercado de trabalho atinge $8,3 \%$ da população negra enquanto atinge "apenas" 34,2\% (trinta e quatro inteiros e dois centésimos por cento) da população branca. Se a resposta para a desigualdade é a educação, outro dado mostra que o Brasil está muito longe de resolver o problema, pois a mesma pesquisa diz que somente $12,8 \%$ (doze inteiros e oito centésimos por cento) dos jovens negros chegaram ao ensino superior enquanto 26,5\% (vinte e seis inteiros e cinco centésimos por cento) dos jovens brancos conseguiram ocupar os acentos das universidades brasileiras. Tal fato chegou a ser motivo de comemoração, pois, antes de políticas afirmativas como as cotas, a distância entre jovens negros e brancos era ainda maior.

De acordo com o último censo disponível do Instituto Nacional de Estudos e Pesquisas Educacionais Anísio Teixeira (INEP), o Brasil conta hoje com 195 universidades sendo que 54,9\% (cinquenta e quatro inteiros e nove centésimos por

Rev. de Direito Sociais e Políticas Públicas | e-ISSN: 2525-9881 | Goiânia | v. 5 | n. 1 | p. 22-43| Jan/Jun. 2019 
cento) são públicas. A forma de acesso também é bem diferente do que a verificada durante o período imperial, hoje há diferentes formas de acesso. Pode-se citar o tradicional vestibular individualizado feito por instituição, a Avaliação Seriada no Ensino Médio e, por último, o Exame Nacional de Ensino Médio (ENEM) (SANTOS, 2016).

A educação, como base fundamental para o desenvolvimento do país, foi alvo, neste contexto, de diversas políticas públicas. Surgiram novas formas de investimento na educação, tais como: o Fundo de Financiamento ao Estudante ao Ensino Superior (Fies), o Programa Universidade para Todos (ProUni) e o Programa Institucional de Bolsas de Iniciação à Docência (Pibid) (Oliveira, 2009). Embora, o acesso à universidade ainda apresente-se muito dificultoso ${ }^{1}$, os dados apresentados pela Organização não Governamental (ONG) OXFAM Brasil (2017), surpreendem ainda mais quando se destaca a diferença social entre brancos e negros no quadro atual brasileiro onde todas as rendas adquiridas pelos brancos, em média, são o dobro do que ganhavam negros, em 2015: "R\$ 1.589,00 em comparação com R \$ 898,00 por mês. Em vinte anos, os rendimentos dos negros passaram de $45 \%$ do valor dos rendimentos dos brancos para apenas 57\%. Se mantido o ritmo de inclusão de negros, observado nesse período, a equiparação da renda média com a dos brancos ocorrerá somente em 2089”.

A ideia de implementação das ações de políticas públicas conhecidas como afirmativas encontra guarita na Constituição Federal de 1988, artigo 5: "Todos são iguais perante a lei, sem distinção de qualquer natureza, garantindo-se aos brasileiros e aos estrangeiros residentes no País a inviolabilidade do direito à vida, à liberdade, à igualdade, à segurança e à propriedade, nos termos seguintes”. Tal regra evidencia a ideia de uma igualdade material (GONÇALVES, 2016). A Igualdade Material funciona como uma evolução da igualdade formal, na perspectiva de que esta, se preocupa com uma conduta negativa do Estado ou de particulares em relação aos demais indivíduos. A primeira tem como norte uma posição muito mais ativa. Como exemplo vislumbra-se uma conduta negativa do Estado quando a Constituição Federal de 1988 apresenta em

\footnotetext{
${ }^{1}$ Segundo Cancian (2016), apenas 14\% (quatorze inteiros por cento) dos adultos brasileiros chegaram ao ensino superior
}

Rev. de Direito Sociais e Políticas Públicas | e-ISSN: 2525-9881 | Goiânia | v. 5 | n. 1 | p. 22-43| Jan/Jun. 2019 
seu preâmbulo a ideia de um Estado democrático destinado a assegurar a igualdade como um dos principais valores da sociedade ou, ainda na igualdade formal, quando proíbe o racismo em seu artigo XLII. A igualdade material não se contenta em buscar virtualmente a situação de igualdade, sendo uma vertente positiva do Estado.

A igualdade será instrumento de justiça quando levar em consideração fatores que podem ser subjetivos e distintos daqueles previstos em lei. Nesse sentido o Supremo Tribunal Federal (STF) já decidiu pela constitucionalidade de diversas aplicações de medidas legais visavam, em tese, o uso de igualdade substancial. É pertinente ao presente estudo a decisão da Arguição de Descumprimento de Preceito Fundamental - ADPF n. 186 que questionava se o princípio da igualdade estaria sendo violado quando a UnB (Universidade de Brasília) começou a aplicar a políticas étnicoraciais para o ingresso na respectiva universidade. A discriminação positiva em questão foi considerada constitucional pelo tribunal, mas a decisão passou longe de gerar consenso na sociedade e no mundo acadêmico. (,BRASIL, STF, 2016) (RAMOS, 2014).

O entendimento é de que a igualdade material existe quando o Estado é ativo em políticas públicas proporcionais, com ações afirmativas para combater os privilégios e estabelecer a segurança jurídica. De outra sorte, enquanto houver uma justiça distributiva de natureza universal o caminho percorrido será o da desigualdade.

Segundo Liberati (2013), a concepção de um Estado liberal foi repensada no Brasil, pois este modelo, apesar de marcar uma ruptura no arbítrio estatal, caracteriza-se por sua omissão face aos problemas sociais, estando em dissonância como o proclamado pelo Estado de Bem Estar. Assim, segundo o artigo, Human Rights and Justice: Youth Perceptions in Dialogue with Public Policies in Brazil de Ana Maria Eyng, Thais Pacievitch, Maria de Lourdes do Prado Krüger D’Almeida, ano 2016, o ensino superior no Brasil, advindo por meio de vestibulares, não passa de um ranking de exames de alto grau de seletividade; o que favorece a desigualdade. O Brasil convive com número muito limitado de vagas em instituições públicas para carreiras de maior status social e mais valorizadas sócio-economicamente, destinadas, assim, a apenas uma parcela da juventude brasileira qual pertence a classes médias e altas, pois, somente a

Rev. de Direito Sociais e Políticas Públicas | e-ISSN: 2525-9881 | Goiânia| v. 5 | n. 1 | p. 22-43| Jan/Jun. 2019 
população que tem acesso a uma educação básica, realizada em escolas particulares com meios financeiros satsfatórios para investir na educação, cara, estão condicionadas para os testes.

Em relação aos processos de inclusão / exclusão, Bauman (1998) aponta que duas estratégias alternativas e complementares foram desenvolvidas de forma intermitente, sendo possível perceber que tais estratégias foram e ainda são adotadas pelas instituições de ensino: a "antropoêmica", que é considerado para o processo de assimilação dos sujeitos, em outras palavras, "faça o diferente, similar"; e "antropofágica", que resulta na exclusão em si, por meio da segregação para outras áreas, ou a simples expulsão de diferentes, desiguais. Bauman (1998), discorre que a superação da exclusão requer políticas públicas cotidianas que valorizem os direitos humanos, a justiça e a educação intercultural, correlacionadas de maneira interdependentes.

O que se pode concluir é que o Estado brasileiro não é capaz de fornecer, por exemplo, uma educação superior condizente com o disposto no artigo $5^{\circ}$, supracitado, mesmo considerando o aumento de recursos na educação nos últimos anos conforme atesta o Instituto Nacional de Estudos e Pesquisa Educacionais Anísio Teixeira. Essencialmente, a política pública é uma ação, isto é, uma conduta positiva do Estado que visa um bem comum, levando em conta fatores como os autores responsáveis e a discricionariedade na implantação de tais medidas, Bobbio menciona que "o problema fundamental em relação aos direitos humanos hoje não é tanto justificá-los, mas protegê-los. Este é um problema não filosófico, mas político ” (2004, p. 43). Neste sentido, surge a correlação do histórico apontado em tópicos anteriores, deste artigo, de que seria justo a promoção de uma política pública que amenizasse a condição daqueles que a história não tratou de maneira equânime.

Nesse sentido a Lei n. 12.711, de 27 de agosto de 2012 buscou reverter a situação de disparidade dos brasileiros ao menos no que diz respeito ao acesso de jovens à universidade. Tal atitude governamental, apesar dos elogios, não constituiu uma unanimidade, na sociedade em geral esse assunto causa a exaltação de muitas contradições ideológicas, conforme verifica-se na ADPF 186 do Distrito Federal

Rev. de Direito Sociais e Políticas Públicas | e-ISSN: 2525-9881 | Goiânia | v. 5 | n. 1 | p. 22-43| Jan/Jun. 2019 
proposta pelo partido político, Democratas, contra a política administrativa de cotas da UnB. Na exordial, o referido partido político defendia que a política compensatória atentava contra o princípio da igualdade, vez que, ainda segundo o partido, tal política concederia benefício demasiado para os negros de classe média e que, ainda, submeter candidatos ao ingresso naquela universidade à verificação do fenótipo seria como instalar um "Tribunal Racial”. (BRASIL, STF, 2016).

Isso quer dizer que fatores como a ancestralidade são levados em conta, dado o contexto histórico próximo de escravidão predominantemente negra. Mesmo no século XXI, a discriminação ainda existe, ainda que totalmente avesso aos preceitos constitucionais, vinculado a percepção de mundo baseada nas "cores" das pessoas (SANTOS, 2010). Sabendo disso, a ação afirmativa positivada na Lei n. 12.711 de 27 de agosto de 2012 estabeleceu que as cotas devem levar em conta fatores raciais. Tal situação pode ser observada mais precisamente com a leitura do art. $3^{\circ}$ da referida lei, a saber:

Art. $3^{\circ}$. Em cada instituição federal de ensino superior, as vagas de que trata o art. 1o desta Lei serão preenchidas, por curso e turno, por autodeclarados pretos, pardos e indígenas e por pessoas com deficiência, nos termos da legislação, em proporção ao total de vagas no mínimo igual à proporção respectiva de pretos, pardos, indígenas e pessoas com deficiência na população da unidade da Federação onde está instalada a instituição, segundo o último censo da Fundação Instituto Brasileiro de Geografia e Estatística IBGE.

O conceito de raça vem sendo alvo de muitas críticas. Ora tratado de modo amplo, ora de modo restrito, Silva (2010, p. 53): “Aos olhos da ciência da biologia, no entanto, uma raça é um grupo de indivíduos aparentados por casamentos entre si, isto é, uma população que se distingue das outras populações pela frequência relativa de certas características hereditárias.” No Brasil atual, a questão de raça, relevante para o presente estudo, considera os fatores sociológicos, isto é, como a sociedade trata a questão racial, segundo Assis e Kümpel: “... a população brasileira é, na sua maioria, composta de mestiços, cuja cultura expressa uma espécie de sincretismo cultural, qual lhe imprime uma configuração própria e isso certamente influencia o comportamento e provoca certa tolerância” (2011, p. 41-42).

Rev. de Direito Sociais e Políticas Públicas | e-ISSN: 2525-9881 | Goiânia| v. 5 | n. 1 | p. 22-43| Jan/Jun. 2019 
Os negros ainda padecem do mínimo necessário para o exercício da cidadania, qual seja, o acesso à educação, pois uma parte da população brasileira, na sua maioria negros e mulatos, encontra-se excluída do mercado de trabalho formal ou ocupa apenas posições subalternas ou no mercado de emprego clandestino. Conforme pensa Souza (2010), a educação é um instrumento essencial para o desenvolvimento de um país. Ao reservar, temporariamente, parte das vagas para os estudantes que cursaram o ensino médio predominantemente em escolas públicas e definindo um teto de renda para fazer parte do sistema de cotas o legislador corrige a falsa meritocracia fundada na igualdade formal. Sendo importante citar Bauman, no seu conceito de "limites naturais":

(...) à liberdade de escolha de que desfrutam até os mais livres dos grupos que buscam o poder e nele se sustentam, os limites impostos pelo ambiente social e econômico em que operam, e pela substância de sua operação; limites que continuam imunes mesmo aos estratagemas mais inteligentes e engenhosas, e, portanto, quase insuperáveis. (BAUMAN,2013, p.55)

A igualdade diante do estudo fica totalmente comprometida quando o poder econômico ou social está nas mãos de poucos. Manter a estrutura social com base em mecanismos liberais clássicos não alcançaram no plano real a efetivação da igualdade no acesso ao ensino superior. Pelo contrário se mostrou dificultoso para aqueles que não nasceram em famílias das camadas favorecidas economicamente. Restou, então, sob um manto de pretensa igualdade formal e uma falsa meritocracia; uma realidade em que o jovem negro e pobre, salvo raras exceções, não acessa o ensino superior. Consequentemente, resta para esses jovens os subempregos com baixas remunerações e a ossificação social. Tal pensamento pode ser observado no seguinte trecho de Castilho:

Justificar ou explicar instituições sociais e contingências de desigualdades com base na afirmação de uma pretensa meritocracia justa, neste panorama, parece representar a inversão do real nexo de causalidade existente. Os méritos, em si, não dependem apenas das qualidades e dotes naturais, mas, em grande parte, são resultados de estruturas que beneficiam pessoas já suficientemente abastadas, que impedem, ao mesmo tempo, o desenvolvimento de talentos presentes em sujeitos dotados de parcos bens materiais. Em suma, não são os méritos que conformam as estruturas sociais, mas o contrário. (CASTILHO, 2009, p. 62)

Rev. de Direito Sociais e Políticas Públicas | e-ISSN: 2525-9881 | Goiânia| v. 5 | n. 1 | p. 22-43| Jan/Jun. 2019 
O sistema de educação superior gratuito passou a ser ocupado não com base em mérito, mas sim com base no investimento que cada estudante tinha ao seu dispor. $\mathrm{O}$ parlamento entendeu que tal situação era completamente insociável com a Constituição e procurou compensar os estudantes que por algum motivo não tinham o mesmo poder de investimento, sendo esta a oposta da reconstrução, responsável pela concretização da norma. Segundo Passos (2014), o direito à inserção vai além do direito a subsistência, pois visa garantir a utilidade social do indivíduo por intermédio de um imperativo moral: a cidadania social identificada como "[...] o conjunto de direitos e obrigações que possibilita a participação igualitária de todos os membros de uma comunidade nos seus padrões básicos de vida".

O século XIX confundia reconstrução com assistencialismo. A solidariedade pregava uma obrigatoriedade aos pobres, não observando o centro do problema, o indivíduo desprovido de oportunidades. Esse tipo de política pública positivada, fundada em bases liberais, não pode mais ser admitido na modernidade, sendo imperativa a adoção de políticas públicas voltadas à reconstrução do vínculo social. A política pública de concessão de cotas em universidades públicas seja levando em consideração o critério social ou racial deve ser observado com o máximo cuidado pela administração pública. Pois, se sua aplicação for apenas pontual, a sua essência tende a ser prejudicada e, assim, corre o risco de se tornar uma espécie de privilégio às avessas. A aplicação da igualdade material se faz necessária e urgente.

Vale aqui apresentar, informações de dados advindos da pesquisa realizada em 2014, por Marcus Eugênio Oliveira Lima, Paulo Sérgio Da Costa Neves e Paula Bacellar E Silva, advinda do artigo: A implantação de cotas na universidade: paternalismo e ameaça à posição dos grupos dominantes, da Universidade Federal de Sergipe (UFS), antes da implantação de cotas em 2005, época de intenso debate sobre o tema, e depois de sua implantação, na primeira turma de cotistas em 2010, cujo os resultados encontrados indicaram que:

(...) ainda que considerassem desigual e injusta a situação econômica dos negros comparativamente aos brancos no Brasil, os estudantes se mostraram em sua maioria contrários às cotas sociais e, sobretudo, às cotas raciais.

Rev. de Direito Sociais e Políticas Públicas | e-ISSN: 2525-9881 | Goiânia | v. 5 | n. 1 | p. 22-43| Jan/Jun. 2019 
Todavia, enquanto a oposição às cotas sociais decresceu com a sua implantação - em 2005 eram $67 \%$ e em 2010 foram 54,1\% -, cresceu a oposição as cotas raciais - 9,8\% eram favoráveis antes de implantadas, $0 \%$ depois da implantação. (LIMA, NEVES \& SILVA, 2014, p.)

Uma vez observadas as desigualdades sociais ou raciais no meio fático, nasce a verdadeira obrigação de todos os Poderes da República de combater a desigualdade. Visa-se, em tese, com uma ação afirmativa a promoção da igualdade, e o combate a prolongação do privilégio, nessa linha que segue a Lei n. 12.711 de 29 de agosto de 2012, lei das cotas em universidades públicas. O prazo é importante para se verificar se a política de cotas proporcionou alguma melhora no acesso e permanência nas universidades públicas. Em segundo lugar, é importante ter a referida ação como um "remédio", uma medida urgente e paliativa, que não exclui, em nenhuma circunstância, investimentos pesados e conscientes em educação de base. E, por último, a prolongação no tempo de uma política como a que está em tela pode se transformar num privilégio, por mais justo que pareça a ação atualmente.

Avançando nas discussões sobre ações afirmativas de cotas, verificou-se que para atingir a situação desejada de igualdade formal era necessário pensar em estratégias efetivas de permanência da população afrodescendente que extrapolassem o âmbito das Universidades públicas, já que uma vez instruídos, estes indivíduos pudessem ascender socialmente através do trabalho e contribuir com o conhecimento adquirido com a sociedade a qual integram. Surgem, portanto, no país o debate sobre as cotas em concursos públicos, destinados à carreira de Estado que culminou na Lei 12990/2014. O texto legal faz reserva de $20 \%$ das vagas em concursos para a administração pública federal direta e indireta, para autarquias, agências reguladoras, fundações públicas, empresas públicas e sociedades de economia mista controladas pela União.

Em realidade, tanto a Lei 12711/2012, bem como a Lei 12990/2014, são frutos do Estatuto da Igualdade Racial, Lei 12288/2010 que em seu texto enfatiza a necessidade de instituir sistema de cotas através dos seguintes instrumentos: adoção de medidas, programas e políticas de ações afirmativas; implementação de medidas, visando à promoção da igualdade nas contratações do serviço público e o incentivo à

Rev. de Direito Sociais e Políticas Públicas | e-ISSN: 2525-9881 | Goiânia | v. 5 | n. 1 | p. 22-43| Jan/Jun. 2019 
adoção de medidas similares em instituições privadas; possibilidade criar critérios para ampliação da participação de negros nos cargos em comissão e funções de confiança do serviço público federal. Trata-se de uma macropolítica fundada no reconhecimento da igualdade formal do Estado Democrático de Direito.

\section{Considerações Finais}

Partindo do pressuposto que políticas públicas são instrumentos para a concretude de direitos fundamentais, a presente pesquisa teve o intuito de realizar uma investigação metodológica destas a partir de um prisma sócio-jurídico. Isto porque é essencial para este estudo o entendimento de que o Estado tem o dever de interferência nas relações sócio-jurídicas para modificar ou aperfeiçoar a garantia dos direitos sociais a fim de cumprir os princípios da equidade e da dignidade da pessoa humana.

No Brasil, a atuação do Estado tem se dado de forma mais ampla, visto que a organização democrática do país se deu de forma tardia e resta ainda a árdua tarefa de congregar situações de desigualdade com oportunidades sociais. Neste sentido, a presente análise recaiu sobre o direitos sociais, mormente, na vertente da Educação como direito essencial ao exercício da cidadania bem como parte essencial do desenvolvimento humano. Identificado em seu cerne como problema público o acesso ao ensino superior, vagas nas universidades públicas, além das estratégias efetivas de permanência, a pesquisa se aprofundou no sistema de cotas e no seu contraponto meritocrático, como visão distorcida da realidade social.

Neste contexto, partiu-se da convicção de que políticas públicas têm por objetivo alcançar a igualdade material com vistas a preencher as necessidades individuais e a atender ao interesse público. Mas para que isto seja alcançado necessário se faz que o Estado alcance o sentido de equidade fundado, nas concepções de Rawls, na cooperação entre cidadãos razoáveis e racionais para alcançar os fundamentos de uma sociedade fraterna e plural como intenta o texto constitucional brasileiro. Para isto, o planejamento estatal deve incluir em sua prática ações afirmativas com o objetivo precípuo de possibilitar oportunidades iguais de modo proativo.

Rev. de Direito Sociais e Políticas Públicas | e-ISSN: 2525-9881 | Goiânia| v. 5 | n. 1 | p. 22-43| Jan/Jun. 2019 
Assim surgem no cenário nacional a implantação do sistema de cotas raciais como instrumento de acesso às vagas nas universidades brasileiras e, posteriormente como acesso aos cargos efetivos providos por concurso público na administração pública brasileira. Tais medidas parecem ser as viáveis para corrigir as distorções históricas de uma Educação construída em prol das elites locais. Em seu cerne está o debate sobre a concorrência desleal entre aqueles que são socialmente privilegiados e os que estão à margem do sistema, como ocorre com a população afrodescendente no Brasil. Estas desigualdades, longe de serem apenas um discurso de classe, são comprovadas através de pesquisas realizadas no país.

A ineficiência do Estado em oferecer vagas em universidades públicas e gratuitas a todos os cidadãos, desrespeitando, portanto o artigo $5^{\circ}$. da Constituição Federal faz com que seja impositivo ao menos tornar viável o acesso através de mecanismos que coroem o princípio da igualdade material. É neste sentido que, o que muitos denominam de distorção do sistema de valores, afirmações estas eivadas de preconceitos, é na verdade uma forma de discriminação positiva. A escassez de recursos públicos disponíveis como ocorre com as vagas nas universidades públicas faz com que conflitos sociais surjam, como ocorreu na ADPF 186, e é neste momento que a intervenção estatal de reconhecimento de desigualdades se torna importante.

No caso in loco, a intervenção do Estado se deu através de uma macropolítica, qual seja, a edição do Estatuto da Igualdade Racial, Lei 12288/2010, colocando no centro da agenda política o reconhecimento de uma desigualdade histórica brasileira e instituindo mecanismos de intervenção para diminuição das disparidades. O sistema de cotas surge aí como instrumento impositivo e necessário para o cumprimento da política pública. Desse modo, duas outras legislações nascem para dar vazão a esta necessidade: a Lei 12711/2012, destinada às cotas para acesso às vagas na universidade; e a Lei 12990/2014 para a criação de cotas de acesso às vagas de cargos efetivos na administração pública como estratégia efetiva permanente. Estas políticas pontuais têm por escopo a implementação de políticas de acesso à população afrodescendente nos campos educacionais e do trabalho fundadas na igualdade de oportunidades.

Rev. de Direito Sociais e Políticas Públicas | e-ISSN: 2525-9881 | Goiânia | v. 5 | n. 1 | p. 22-43| Jan/Jun. 2019 
POLÍTICAS PÚBLICAS NO BRASIL E O LUGAR DO SUJEITO: LEI, JUSTIÇA E REPRESENTAÇÕES SOCIAIS NO ACESSO À EDUCAÇÃO SUPERIOR BRASILEIRA E NAS

ESTRATÉGIAS EFETIVAS DE PERMANÊNCIA

\section{REFERÊNCIAS:}

ABREU, C. Capítulos de história colonial: 1500 - 1800. Brasília, Brasil: Conselho Editorial do Senado Federal, 1998.

ALVES, J. A. A arquitetura internacional dos direitos humanos. São Paulo, Brasil. FTD, 1997

BAUMAN, Z. Danos colaterais, Desigualdades sociais numa era global. Rio de Janeiro, Brasil: Zahar, 2013.

BRASIL. Decreto no 19.851, de 11 de Abril de 1931. Fins do Ensino Universitário, Rio de Janeiro, DF. Disponível em: http://www2.camara.leg.br/legin/fed/decret/19301939/decreto-19851-11-abril-1931-505837-publicacaooriginal-1-pe.html. Acesso em 23 de novembro de 2018

BRASIL. Instituto Brasileiro de Geografia e Estatística. Brasil: 500 anos de povoamento. Rio de Janeiro, Brasil. 2000.

BRASIL. Lei no 3.353, de 13 de Maio de 1888. Declara extinta a escravidão no Brasil. Rio de Janeiro, mai 1888. Disponível em:

http://www.planalto.gov.br/ccivil_03/leis/lim/LIM3353.htm. Acesso em 23 de novembro de 2018

BRASIL. Presidência da República. Lei no 12.711, de 29 de Agosto de 2012. Dispõe sobre o ingresso nas universidades federais e nas instituições federais de ensino técnico de nível médio e dá outras providências. Brasília, DF. Disponível em:

http://www.planalto.gov.br/ccivil_03/_ato2011-2014/2012/lei/112711.htm. Acesso em

23 de novembro de 2018

BRASIL. Presidência da República. Lei 12990, 9 de junho de 2014. Reserva aos negros $20 \%$ (vinte por cento) das vagas oferecidas nos concursos públicos para provimento de cargos efetivos e empregos públicos no âmbito da administração pública federal, das autarquias, das fundações públicas, das empresas públicas e das sociedades de economia mista controladas pela União. Disponível em

http://www.planalto.gov.br/ccivil_03/_ato2011-2014/2014/lei/112990.htm. Acesso em 23 de novembro de 2018.

BRASIL. Presidência da República. Lei 12888 de 20 de julho de 2010. Estatuto da Igualdade Racial. Disponível em http://www.planalto.gov.br/ccivil_03/_Ato20072010/2010/Lei/L12288.htm. Acesso em 23 de novembro de 2018.

BRASIL .Supremo Tribunal Federal. Argüição de descumprimento de preceito fundamental: ADPF 186. Relator: Ministro Ricardo Lewandowski. DJ: 02/03/2016. JusBrasil. Disponível em:

https://stf.jusbrasil.com.br/jurisprudencia/311461780/arguicao-de-descumprimento-de-

Rev. de Direito Sociais e Políticas Públicas | e-ISSN: 2525-9881 | Goiânia | v. 5 | n. 1 | p. 22-43| Jan/Jun. 2019 
POLÍTICAS PÚBLICAS NO BRASIL E O LUGAR DO SUJEITO: LEI, JUSTIÇA E REPRESENTAÇÕES SOCIAIS NO ACESSO À EDUCAÇÃO SUPERIOR BRASILEIRA E NAS

ESTRATÉGIAS EFETIVAS DE PERMANÊNCIA

preceito-fundamental-adpf-186-df-distrito-federal-0005708-8420090010000. Acesso em 23 de novembro de 2018

BUCCI, Maria Paula Dallari. Políticas públicas: reflexões sobre o conceito jurídico.

São Paulo: Saraiva, 2006.

CANCIAN, N. Só $14 \%$ dos adultos brasileiros têm ensino superior. Folha de S.

Paulo. Disponível em: http://www1.folha.uol.com.br/educacao/2016/09/1813715-so-14dos-adultos-brasileiros-tem-ensino-superior-diz-relatorio-da-ocde.shtml acesso em 23 de novembro de 2018. Acesso em 23 de novembro de 2018.

CASTILHO, R. Justiça Social e Distributiva - Desafios para concretizar direitos sociais. São Paulo, Brasil: Saraiva, 2009.

CASADO, F. Napoleão. Direitos Humanos Fundamentais. São Paulo, Brasil: Saraiva, 2012

CARVALHO, M. M. C. Reformas da instrução pública. 500 anos de Educação no Brasil. 5. ed. Belo Horizonte, Brasil: Autêntica, 2015

COUTRIM, G., FERNANDES, M. Conecte Filosofar. São Paulo, Brasil: Saraiva, 2011.

CUNHA, A. L. Ensino Superior e Universidade no Brasil. 500 anos de Educação no Brasil. 5. ed. Belo Horizonte, Brasil: Autêntica, 2015

CURY, C. R. J. A educação como desafio na ordem jurídica. 500 anos de Educação no Brasil. 5 ed. Belo Horizonte, Brasil: Autêntica, 2015

EYNG, Ana Maria; PACIEVITCH, Thais; D'ALMEIDA, Maria de Lourdes do Prado Krüger. Human Rights and Justice: Youth Perceptions in Dialogue with Public Policies in Brazil, 2016.

ESPING - ANDERSEN, Gosta .The three worlds of welfare capitalism. Cambridge: Polity Press, 1990.

FAUSTO, B. História do Brasil. 11 ed. São Paulo, Brasil: Edusp, 2003.

GEORGES, R. A distância que nos une: um retrato das desigualdades brasileiras. São Paulo, Brasil: Brief Comunicação, 2017.

GOMES, Joaquim Benedito Barbosa. As ações afirmativas e os processos de promoção da igualdade efetiva. Brasília, DF. Conselho da Justiça Federal, Centro de Estudos Judiciários; AJUFE; Fundação Pedro Jorge de Mello e Silva; The Britsh Council. Série Cadernos do CEJ, v. 24. 2001

HESSE, K. et Al. . Significado de los derechos fundamentales. In HESSE, K. Manual de derecho constitucional, Madrid, Espanha: Marcial Pons, 1996.

Rev. de Direito Sociais e Políticas Públicas | e-ISSN: 2525-9881 | Goiânia | v. 5 | n. 1 | p. 22-43| Jan/Jun. 2019 
LOUREIRO, J. C. Adeus ao Estado social? A segurança social entre o crocodilo da economia e a medusa da ideologia dos "direitos adquiridos". Coimbra, Portugal: Coimbra Editora, 2010.

LUÑO, A. E. P. Derechos humanos, Estado de Derecho y Constitución. 9 ed. Madrid, Espanha: Tecnos, 2005

MELLO, C. A. de B. O conteúdo jurídico do princípio da igualdade. São Paulo, Brasil: Malheiros, 2013.

MINTO, L.W. Teoria do capital humano. In: LOMBARDI, J.C; SAVIANI, D.;

NAGEL,L.H. Educação via Banco Mundial: Imposição ou servidão necessária? São José de Costa Rita. Anais, 2001. Disponível em: http://www.historia.fcs.ucr.ac./congred/pron-brasil. Acesso em 23 de novembro de 2018.

OLIVEIRA, J. Saiba como funciona sistema de ensino superior no Brasil. Portal Brasil. Disponível em: http://www.brasil.gov.br/educacao/2009/11/ensino-superior . Acesso em 23 de novembro de 2018

PARSONS, W. Políticas públicas: una introducción a la teoría y la práctica del análisis de políticas públicas. Buenos Aires, Argentina: Miño y Dávila Editores, 2007.

RAMOS, A. de C. Curso de direitos humanos. São Paulo, Brasil: Saraiva, 2014

RAWLS, J. Political Liberalism; tradução Álvaro de Vita. - Ed. ampl. - São Paulo: editora WMF Martins Fontes. (Biblioteca jurídica WMF), 2011.

SAMPAIO, J. S. O controle jurisdicional das políticas públicas de direitos sociais. Coimbra, Portugal: Coimbra Editora, 2014.

SANTOS, F. 10 números que mostram como está o ensino superior no Brasil. Exame, São Paulo, Brasil. Disponível em: https://exame.abril.com.br/brasil/10numeros-que-mostram-como-esta-o-ensino-superior-no-brasil/ . Acesso em $23 \mathrm{de}$ novembro de 2018.

SILVA, Maurício. Cotas Raciais na Universidade Brasileira e a ideologia da meritocracia. Revista Diálogo Educacional, v. 17, n.54, p. 1207-1221, jul-set, 2017.

SILVA, Tatiana Dias. O Estatuto da Igualdade Racial. Texto para discussão. São Paulo: IPEA, 2012.

SILVA, Tatiana Dias; SILVA, Josenilton Marques. Reserva de Vagas para Negros em Concursos Públicos: Uma análise a partir do Projeto de Lei 6728/2013. Nota técnica n. 17. Brasília: IPEA, 2014.

ZAMORA, M. A. Estado Social y felicidad: la exigibilidad de los derechos sociales en el constitucionalismo actual. Madrid, Espanha: Ediciones del Laberinto. 2007.

Rev. de Direito Sociais e Políticas Públicas | e-ISSN: 2525-9881 | Goiânia | v. 5 | n. 1 | p. 22-43| Jan/Jun. 2019 
POLÍTICAS PÚBLICAS NO BRASIL E O LUGAR DO SUJEITO: LEI, JUSTIÇA E REPRESENTAÇÕES SOCIAIS NO ACESSO À EDUCAÇÃO SUPERIOR BRASILEIRA E NAS ESTRATÉGIAS EFETIVAS DE PERMANÊNCIA 